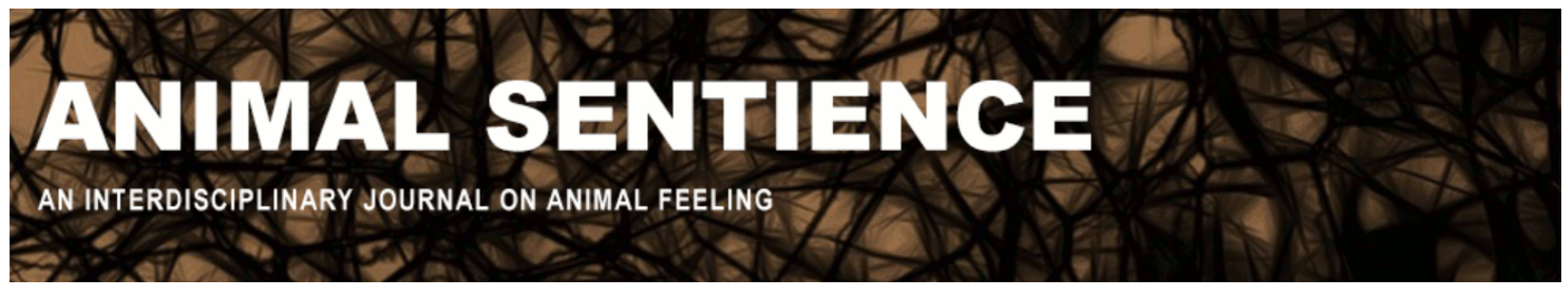

Safina, Carl (2016) Fish pain: A painful topic. Animal Sentience 3(41)

DOI: $10.51291 / 2377-7478.1076$

Date of submission: 2016-01-09

Date of acceptance: 2016-01-11

(c) (i)

This article has appeared in the journal Animal

Sentience, a peer-reviewed journal on animal

cognition and feeling. It has been made open access,

free for all, by WellBeing International and deposited

in the WBI Studies Repository. For more information,

please contact

wbisr-info@wellbeingintl.org.

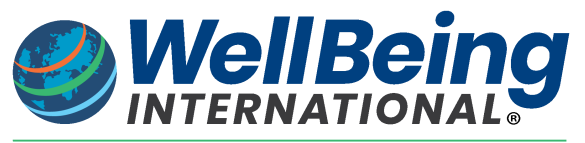

SOLUTIONS FOR PEOPLE, ANIMALS AND ENVIRONMENT 


\title{
Fish pain: A painful topic
}

Commentary on Key on Fish Pain

\author{
Carl Safina \\ Marine \& Atmospheric Sciences \\ Stony Brook University
}

\begin{abstract}
If fish cannot feel pain, why do stingrays have purely defensive tail spines that deliver venom? Stingrays' ancestral predators are fish. And why do many fishes possess defensive fin spines, some also with venom that produces pain in humans? These things did not evolve just in case sentient humans would evolve millions of years later and then invent scuba. If fish react purely unconsciously to "noxious" stimuli, why aren't sharp jabbing spines enough? Why also stinging venom?
\end{abstract}

Carl Safina csafina@safinacenter.org is the inaugural endowed professor for nature and humanity at Stony Brook University, where he co-chairs the Alan Alda Center for Communicating Science and is founding president of the not-for-profit Safina Center. Beyond Words: What Animals Think and Feel is Carl's seventh book. http://safinacenter.org/about-carl-safina/

Key (2016) seems an excellent neurobiologist, but he is less convincing as a logician. He launches with the seemingly inarguable truism that to address whether fish can feel pain, "it is necessary to first understand the neural basis of pain in humans, since it is the only species able to directly report on its feelings." But no logic supports this conflation of pain and human speech.

Many non-human animals "report" pain vocally, with squeals or whines. These reports from non-human beings-especially social species - are essentially the same as a human painreporting by screaming. It's analogous to humans reporting pain in a language we happen not to speak. If I don't speak Vietnamese, that doesn't mean that a Vietnamese-speaking human isn't "able to directly report on its feelings." And if I am not a dog or pig, that doesn't mean the dog or pig isn't expressing pain.

Our ability to understand the Vietnamese-speaking human, the whining dog, or the squealing pig depends partly on our ability to judge circumstances. Humans might lie about pain for purposes ranging from emotional manipulation to humor, leaving us to confirm human pain partly by judging the circumstances surrounding their report - as we'd do with non-humans.

Key's theory is, "structure determines function." Agreed, it's sensible that the same brain structures in closely related species function similarly, and that structures producing pain in human brains produce pain in other animals possessing those structures. But there seems no 
reason that pain sensations cannot be produced by other structures in other species. That would be like concluding that because birds use feathers, bats and insects cannot fly.

Key looks for his proof in the structures of the nervous system. I look for mine in the logic and adaptive function of behaviors. My assumption is that performance, rather than neural structure, is the best evidence of mental capacity. Yes, neural structures and connections that produce pain in humans would be a good and perhaps sufficient indication of pain production in other animals. But it seems to me to be as logical to infer perceptions from behavior as it is logical to infer perceptions from brain structure.

It is logical to infer that when a non-human appears to feel pain when exposed to things that cause pain in humans, they feel pain. Brains might create the same perceptions in different ways. There are different ways to wire a mind. Parrots, with tiny brains, use tools. Ravens solve puzzles better than dogs.

Lack of homologous structure seems no proof that an animal cannot feel pain. Indeed, the behavior of an animal in response to things that cause pain in humans seems better evidence of the presence or absence of pain perception than probing a brain, since pain is a subjective experience that motivates certain behaviors.

Why would brains manufacture pain? The only answer I can think of is that pain is a perception that helps animals avoid or withdraw from stimuli that can harm them. I admit that the weakness in my argument is that it appeals only to logic and adaptive function, whereas Key knows a lot about human brains. However, l'd like to take that logic a bit further and ask why the genomes of other animals and even plants would invest so heavily in generating defensive structures and behaviors that can cause pain? A stingray's spine is entirely a defensive structure, and yet to that structure it adds venom that produces pain. Granted, reports of stingraygenerated pain come from humans. But who are the stingrays' main potential predators? Fish, of course, as well as sharks and marine mammals. Stingrays evolved these defenses millions of years before the planet's first neocortex.

Doesn't a defensively stinging creature protect itself by inducing pain? Isn't pain the thing that animals perceive as noxious about spines, stinging hairs and bad-tasting chemicals? Key claims that animals don't actually need to feel any of this. But many defense-deploying animals use bright colors to warn potential predators that they have irritating hairs or venomous spines or bites, and predators avoid them. The warning colors must be backed up by the actual noxious defense, or it doesn't work. It is nearly inconceivable that a predator would avoid the threat of a nasty sensation that it could not feel. It seems logically inescapable that pain is what makes all this work. Stingers, thorns, biting ecto-parasites, and so forth are extremely widespread, so the perception of pain is probably very ancient and equally widespread.

I assume that fish can feel panic, stress, and pain. But while they appear to show panic and stress, they don't seem to exhibit much of a pain-like response when hooked. I assume that a fish in acute pain would not pull vigorously against a pain-inducing hook. So it seems to me that, 
like people who have just received a major injury and are in panic or shock mode, fish brains probably suppress pain while they are struggling for their lives (Melzack \& Wall 1967). I can report that getting my foot pierced by a fish hook the size of my index finger produced zero pain initially; in fact at first I didn't even realize it had happened. My body went into fight-or-flight mode: My arteries dilated to receive more blood but, because I was neither fighting nor running, my pulse did not rise, and a drop in blood pressure resulted in my feeling faint - but still no pain. Is similar pain-suppression happening in a hooked fish? It seems likely.

How much pain is a fish capable of feeling? Many fish seldom touch anything except their prey, and many prey have spines. I would not expect fish to have dense touch and pain receptors in their lips as we do. And it appears that pain receptors are relatively sparse around the head (Chervova and Lapshin 2004). But they do exist, so one must ask what an animal does with pain receptors.

The most perplexing thing in Key's target article is his contention that response to or withdrawal from "noxious" stimuli can be accomplished even in mammals with no sensation of the stimulus. If so, what is the value of our capacity for perceiving pain? It is sometimes asserted that humans pull away from a hot stove before sensing pain. This is not my experience. Isn't that why we get burned by hot coffee or frying pan handles - precisely because the damage to tongue or fingers is done before we feel pain and pull away?

Key cites experiments indicating that complex escape behaviors can be performed without any sensation of the stimulus at all. Key then asks and answers himself: "What then do noxious stimuli feel like to a fish? The evidence best supports the idea that they don't feel like anything to a fish." Actually watching fish, though, produces different impressions.

I once began tossing chunks of fish to a blue shark that we'd attracted to my boat with a trail of mashed-up fish. The shark was feeding very actively, quickly gobbling each chunk of fish that I tossed. When a stinging species of jellyfish called a lion's mane drifted out from under the boat, the shark immediately bit the jelly as though mistaking it for a larger bit of mashed fish. But the shark instantly shook its head vigorously, ejecting the jelly. Contrastingly, I have watched leatherback turtles feeding on lion's mane jellyfish with no apparent discomfort. Stinging jellies are a main prey of these turtles. The shark showed behavior consistent with pain; the turtles do not.

Key implies that the "noxiousness" is in the stimulus rather than the perception. If so, then the jellyfish with its stinging tentacles firing thousands of venomous nematocysts is equally noxious to shark and turtle. But the shark appeared to perceive discomfort, while the turtles appear quite obviously immune to feeling pain from jellyfish stings. So noxiousness is in the beholder not in the stimulus - and response behavior is strong evidence of pain perception or the lack thereof.

Key believes that fish feel nothing at all, ever. But Key also believes, quite oddly I think, that humans feel and think nothing when getting dressed and going to work. Key (2015) has recently 
written: "I contend that it doesn't feel like anything to be a fish. Interestingly, much of our own lives are led without attending to how we feel. We just get on with it and do things. Most of the time we act like automatons. We manage to get dressed in the morning, or walk to the bus station, or get in the car and drive to the shops without thinking about what it feels like. Consequently, much of what we do is accomplished non-consciously."

If that's how fish experience "nothing," then fish have far richer experiential and inner lives than I ever imagined. Key seems to have provided us with an unexpected inversion of this debate.

From close experience, I know fish as creatures who are wary, facile in learning, curious, discriminating, often hard to fool, behaviorally inconsistent, and generally quite behaviorally complex (Safina 2016).

Key says pain perception is a difficult problem, not easily provable. True enough. I am not sure anyone has been convinced of anything, or even much enlightened. That might be the most painful thing in this debate.

\section{References}

Chervova, L. S., \& Lapshin, D. N. (2004). Pain sensitivity of fishes and analgesia induced by opioid and nonopioid agents. In: Proceedings of 4th Int. Iran and Russia Conf. Agriculture and natural resources. ShahreKord, Iran.: Published by Shahre Kord Univ (pp. 1420-1425).

Key, B. (2015). Why fish (likely) don't feel pain. Scientia Salon, February 5th.

Key, B. (2016). Why fish do not feel pain. Animal Sentience 2016.003.

Melzack, R., \& Wall, P. D. (1967). Pain mechanisms: A new theory. Survey of Anesthesiology, 11(2), 89-90.

Safina, C. (2016). Animals think and feel: Précis of Beyond words: What animals think and feel (Safina 2015). Animal Sentience 2016.002. 